\title{
Correlation of Expression of CHI3L1 and Nogo-A and their Role in Angiogenesis in Invasive Ductal Breast Carcinoma
}

\author{
AGNIESZKA RUSAK ${ }^{1}$, KAROLINA JABLONSKA ${ }^{1}$, ALEKSANDRA PIOTROWSKA ${ }^{1}$, \\ JEDRZEJ GRZEGRZOLKA ${ }^{1}$, ANDRZEJ WOJNAR ${ }^{2}$ and PIOTR DZIEGIEL ${ }^{1,3}$ \\ ${ }^{1}$ Division of Histology and Embryology, Department of Human Morphology and Embryology, \\ Wroclaw Medical University, Wroclaw, Poland; \\ ${ }^{2}$ Department of Pathology, Lower Silesian Oncology Center, Wroclaw, Poland; \\ ${ }^{3}$ Department of Physiotherapy, University School of Physical Education, Wroclaw, Poland
}

\begin{abstract}
Background/Aim: Chitinase 3 like 1 (CHI3L1) is a secretion glycoprotein. Elevated levels of this protein are observed in cancer diseases. The biological role of $\mathrm{CHI} 3 \mathrm{LI}$ is not yet fully known, but the connection between CHI3L1 and angiogenesis has been shown. Recent reports also describe the association of Nogo isoforms and Nogo-B receptor $(\mathrm{NgBR})$ with a proliferative potential, cancer cell invasiveness, and angiogenesis. The aim of this study was to evaluate the levels of CHI3L1, Nogo-A, Nogo-A/B, and $\mathrm{NgBR}$ and correlate them with clinical-pathological data, to study their role in angiogenesis in invasive ductal breast carcinoma (IDC). Materials and Methods: A total of 77 IDC cases were used in the study. Immunohistochemistry was used to determine the level of expression of CHI3L1, Nogo-A, Nogo-A/B, NgBR and vascular endothelial growth factors (VEGFA, VEGFC and VEGFD). The obtained results were subjected to statistical analysis including clinicalpathological data. Results: A statistically significant positive correlation of CHI3L1 and Nogo-A expression ( $r=0.474$, $p>0.0001)$ and a positive correlation of Nogo-A and VEGFC expression ( $r=0.280, p=0.013)$ were found. Conclusion: CHI3L1 and Nogo-A are important in angiogenesis in IDC.
\end{abstract}

Chitinase 3 like 1 (CHI3L1, YKL-40, HCgp-39, gp-38k) is a 40-kDa glycoprotein composed of 383 amino acids (1). This protein shows a significant homology to the family of chitinase-like proteins (CLPs), but it does not have an enzymatic activity (2). Human CHI3LI gene is located at the

Correspondence to: Agnieszka Rusak, Chalubinskiego 6a, 50-368 Wroclaw, Poland. Tel: +48 717841354(55), Fax: +48 717840082, e-mail: rusakagn@gmail.com

Key Words: CHI3L1, YKL40, Nogo-A, angiogenesis, breast cancer. chromosomal region 1q32.1 and is $8 \mathrm{kbp}$ in size, including 10 exons (2). The function and mechanism of action of CHI3L1 have not yet been fully determined. CHI3L1 regulates cell proliferation (fibroblasts, chondrocytes) and differentiation (macrophages), inflammatory processes, and extracellular matrix reorganization, and also prevents apoptosis (2-4). CHI3L1 involvement in chronic inflammation of varied etiology is commonly described, including autoimmune inflammatory diseases, such as multiple sclerosis (MS) (5-8).

In cancer patients, the concentration of CHI3L1 is elevated and depends, inter alia, on the type and stage of cancer, as well as on the localization of metastases (9). CHI3L1 expression was found in cancer cells and tumorassociated macrophages (TAM) $(10,11)$. An increased serum level of CHI3L1 is considered a negative prognostic factor in breast, lung and ovary carcinoma, as well as in melanoma (5-7). The role of CHI3L 1 as a biomarker e.g. in breast cancer, is still unclear (12-15). The involvement of CHI3L1 in angiogenesis was indicated by studies in human breast cancer, colon cancer, and glioma (11, 15-17).

Nogo isoforms belong to the family of reticulon proteins (RTN) associated with membranes of the endoplasmic reticulum. There are three main isoforms of Nogo in the fourth group of reticulons (RTN4): Nogo-A (RTN4A, 200 kDa), Nogo-B (RTN4B, $55 \mathrm{kDa}$ ) and Nogo-C (RTN4C, $25 \mathrm{kDa})(18-22)$. These proteins are expressed e.g. in the nervous system (Nogo-A, Nogo-B), macrophages (Nogo-A, Nogo-B), skeletal muscle cells (Nogo-A, Nogo-C), as well as in vascular endothelial cells and smooth muscle cells of the blood vessel wall (Nogo-B) (19-22). Reticulons may be involved in processes that include inhibition of neurite growth and axonal regeneration (Nogo-A), promotion of endothelial cell migration and inhibition of migration of smooth muscle cells of the blood vessel wall (Nogo-B), recruitment of leukocytes into the site of chronic or acute 
inflammation, promotion of epithelial-mesenchymal transition (EMT) (NgBR), as well as promotion (Nogo-B, Nogo-C) or inhibition (Nogo-A) of apoptosis $(19,21,23-28)$. Nogo-B was shown to mediate chemotaxis and morphogenesis of endothelial cells by binding to the specific NgBR (29). Nogo proteins, especially Nogo-A, are involved in the pathogenesis of neurodegenerative diseases: multiple sclerosis (MS), amyotrophic lateral sclerosis (ALS) and Parkinson's disease (19, $28,30-33)$. The results of studies on the expression and prognostic value of isoforms of Nogo and $\mathrm{NgBR}$ in cancers, such as melanoma, gastric, lung or breast cancer, are inconclusive (18, 34-38). Angiogenesis is believed to be one of the processes that involve Nogo proteins $(29,39)$.

MAPK and PI3K/Akt are common intracellular pathways involving both CHI3L1 and Nogo. Importantly, it is possible that these two pathways are mutually intersecting $(16,40$ 43 ). Both of the aforementioned signaling pathways have a crucial role in carcinogenesis, promote cancer cell proliferation and migration, inhibit apoptosis and stimulate angiogenesis (44-47).

Previous in vitro studies showed that CHI3L1 is involved in angiogenesis by activating MAPK/ERK and PI3K/Akt pathways in human vessel microvascular endothelial cells, endothelial progenitor cells, as well as in human U87 glioma cells $(11,16,40,48,49)$. In endothelial cells, CHI3L1 promotes bond formation between syndecan-1 (SDC1) and integrin $\alpha_{v} \beta_{3}$, which leads, through FAK $^{861}$ (focal adhesion kinase), to the activation of angiogenesis-promoting MAPK/ERK1/2 pathway (48). In glioma cells, on the other hand, CHI3L1 promotes formation of bonds between syndecan- 1 and integrin $\alpha v \beta 5$, and through FAK $^{397}$ it activates the MAPK/ERK1/2 pathway that increases VEGF expression and also promotes angiogenesis (40). Moreover, FAK ${ }^{397}$ activates the PI3K/Akt pathway that protects glioma cells from apoptosis. In glioma cells, PI3/Akt activation by CHI3L1 can presumably take place also by CHI3L1 binding with the interleukin receptor IL-13R $\alpha 2$ (40).

The importance of Nogo-A as an activator of MAPK/ERK1/2 and PI3K/Akt pathways was demonstrated in an in vivo study on neuronal conductivity and regeneration in mice $(41,42)$. As shown in this study, receptor binding by Nogo-A leads to the activation of RhoA GTPase, PTEN phosphorylation, PI3K/Akt and ERK1/2 activation and, consequently, promotion of neuronal survival (42).

Based on the above literature data, we investigated the potential correlation of CHI3L1 expression with Nogo and $\mathrm{NgBR}$, as well as their involvement in angiogenesis in invasive ductal breast carcinoma (IDC).

\section{Materials and Methods}

Patients and tumors. The study was performed on IDC paraffin sections $(n=77)$ taken from patients diagnosed and operated in the Lower Silesian Oncology Center in Wroclaw between 1999-2002. The control materials were non-malignant breast tissue lesions
(NBTLs) $(n=22)$. Table I shows selected clinical-pathological characteristics of patients. All studies were conducted with the consent of Ethics Committee of Wroclaw Medical University (consents: KB-616/2014 and KB-735/2017).

Immunohistochemistry (IHC). Collected IDC fragments were fixed in $4 \%$ buffered formalin and embedded in paraffin. IHC reactions were performed using Dako Autostainer Link48 (Dako, Glostrup, Denmark) on $4 \mu \mathrm{m}$-thick paraffin sections. Deparaffinization, hydratation and epitope unveiling $\left(97^{\circ} \mathrm{C}, 20 \mathrm{~min}\right)$ were conducted using PT- Link apparatus (Dako) in EnVision ${ }^{\text {TM }}$ FLEX Target Retrieval Solution High $\mathrm{pH}$ (9.0) (Dako) for antibodies against CHI3L1, Nogo-A, NgBR, VEGFA, VEGFD, estrogen receptors (ERs), progesterone receptors (PRs), epidermal growth factor receptor 2 (HER-2) and in EnVision ${ }^{\mathrm{TM}}$ FLEX Target Retrival Solution Low pH (6.0) (Dako) for antibodies against Nogo-A/B, VEGFC and Ki-67. Endogenous peroxidase was blocked using EnVision $^{\mathrm{TM}}$ FLEX Peroxidase-Blocking Reagent (Dako) (5 min). LSAB+ (Dako) visualization system was used for IHC reaction with goat polyclonal CHI3L1 (1:100, $20 \mathrm{~min}, \mathrm{RT})$; R\&D Systems, Minneapolis, MN, USA), Nogo-A (1:800, 20 min, RT; Santa Cruz Biotechnology, Dallas, TX, USA), Nogo-A/B (1:3200, 20 min, RT; Santa Cruz), VEGFC and VEGFD $\left(1: 100,18 \mathrm{~h}, 4^{\circ} \mathrm{C}\right.$; ReliaTech $\mathrm{GmbH}$, Braunschweig, Germany) antibody. Using EnVision ${ }^{\mathrm{TM}}$ FLEX (Dako) system, IHC reactions were performed with VEGFA (1:50, 18 h, $4^{\circ} \mathrm{C}$; Dako), NgBR (1:100, 20 min, RT; Imgenex, San Diego, CA, USA), Ki-67 (clone MIB-1, ready-to-use (RTU), 20 min, RT; Dako), ER (clone ID5, RTU, 20 min, RT; Dako) and PR (clone PR 626, RTU, 20 min, RT; Dako) antibody. Sections were counterstained with hematoxylin (EnVision ${ }^{\mathrm{TM}}$ FLEX Hematoxylin, Dako). HER2 was detected with HercepTest ${ }^{\mathrm{TM}}$ kit (Dako). Visualization systems were used according to manufacturer's recommendations.

Analysis of IHC reactions. Immunohistochemical reactions were analyzed using a light microscope (BX41, Olympus, Tokyo, Japan). Photos were taken with a Panoramic MIDI scanner (3DHISTECH, Budapest, Hungary). Intensities of IHC reactions for CHI3L1, Nogo-A, Nogo-A/B, NgBR, VEGFA, VEGFC, and VEGFD were evaluated with semi-quantitative, 12-points score (IRS) by Remmele and Stegner (50), (Table II). The evaluation of IHC reactions with anti-Nogo-A and anti-Nogo-A/B antibodies was taken into account to estimate the expression of Nogo-B. Expression of ER, PR and HER-2 were evaluated using a $0-3$ score scale: 0 ( $0 \%$ of positive cells), 1 (1-10\% of positive cells), 2 (11-50\% of positive cells), 3 (51-100\% of positive cells). For ER and PR, the reaction was positive for $\geq 1 \%$ of positive cells (as indicated by the score of 1 or higher) (51). For the evaluation of HER2 expression, the reaction was positive if $>10 \%$ of cancer cells showed strong membrane reaction (3 points) (52). Nuclear expression of Ki-67 was estimated with the use of 0-4 score scale. The expression of Ki-67 was evaluated as low when $\leq 25 \%$ (the score of $1-2$ according to the scale) of cells were positive, and as high when $>25 \%$ (the score of 3-4 according to the scale) of cells were positive (53). Median was used as a cut-off point for evaluations with the IRS scale. Cases with IRS score 0-3 were estimated as low CHI3L1 expression, whereas IRS scale $>3$ was indicative of high CHI3L1 expression. In case of VEGFA, VEGFC, and VEGFD, IRS score 0-4 was indicative of low expression, and IRS score 6-12 was indicative of high expression of those proteins. For Nogo-A, no reaction (IRS score 0) vs. positive reaction (IRS score 1-12) was used as a cut-off point (Table III). 
Table I. Analysis of expression of CHI3L1 and Nogo-A (IRS) according to clinical-pathological data; Kruskal-Wallis test, Mann-Whitney U test; medians were used as cut-off points, statistically significant p-values were $<0.05$.

\begin{tabular}{|c|c|c|c|c|c|c|c|c|c|c|c|c|}
\hline \multirow[b]{2}{*}{ Parameters } & \multirow[b]{2}{*}{$\mathrm{N}$} & \multirow[b]{2}{*}{$\%$} & \multicolumn{5}{|c|}{ CHI3L1 N (\%) } & \multicolumn{5}{|c|}{ Nogo-A N (\%) } \\
\hline & & & IRS (0-3) & $\%$ & IRS (4-12) & $\%$ & $p$-Value & IRS (0) & $\%$ & IRS (1-12) & $\%$ & $p$-Value \\
\hline \multicolumn{13}{|l|}{ Age } \\
\hline$>50$ & 51 & 66.2 & 32 & 62.7 & 19 & 37.3 & & 30 & 58.8 & 21 & 41.2 & \\
\hline$\leq 50$ & 26 & 33.8 & 20 & 76.9 & 6 & 23.1 & & 14 & 53.8 & 12 & 46.2 & \\
\hline Total & 77 & 100.0 & 52 & 67.5 & 25 & 32.5 & 0.965 & 44 & 57.1 & 33 & 42.9 & 0.624 \\
\hline \multicolumn{13}{|l|}{ Menopausal status } \\
\hline Pre-menopausal & 27 & 35.1 & 20 & 74.1 & 7 & 25.9 & & 15 & 55.6 & 12 & 44.4 & \\
\hline Post-menopausal & 50 & 64.9 & 32 & 64.0 & 18 & 36.0 & 0.987 & 29 & 58.0 & 21 & 42.0 & 0.934 \\
\hline \multicolumn{13}{|l|}{ Tumor grade } \\
\hline G1 & 7 & 9.1 & 5 & 71.4 & 2 & 28.6 & & 3 & 42.9 & 4 & 57.1 & \\
\hline $\mathrm{G} 2$ & 40 & 51.9 & 26 & 65.0 & 14 & 35.0 & & 23 & 57.5 & 17 & 42.5 & \\
\hline G3 & 30 & 39.0 & 21 & 70.0 & 9 & 30.0 & 0.993 & 18 & 60.0 & 12 & 40.0 & 0.642 \\
\hline \multicolumn{13}{|l|}{ Stage } \\
\hline I & 26 & 33.8 & 20 & 76.9 & 6 & 23.1 & & 16 & 61.5 & 10 & 38.5 & \\
\hline II & 39 & 50.6 & 22 & 56.4 & 17 & 43.6 & & 21 & 53.8 & 18 & 46.2 & \\
\hline III & 11 & 14.3 & 9 & 81.8 & 2 & 18.2 & & 7 & 63.6 & 4 & 36.4 & \\
\hline IV & 1 & 1.3 & 1 & 100.0 & 0 & 0.0 & 0.461 & 0 & 0.0 & 1 & 100.0 & 0.933 \\
\hline \multicolumn{13}{|l|}{ Tumor size } \\
\hline pT1 & 44 & 57.1 & 30 & 68.2 & 14 & 31.8 & & 25 & 56.8 & 19 & 43.2 & \\
\hline pT2 & 26 & 33.8 & 17 & 65.4 & 9 & 34.6 & & 17 & 65.4 & 9 & 34.6 & \\
\hline pT3 & 4 & 5.2 & 3 & 75.0 & 1 & 25.0 & & 1 & 25.0 & 3 & 75.0 & \\
\hline pT4 & 3 & 3.9 & 2 & 66.7 & 1 & 33.3 & 0.804 & 1 & 33.3 & 2 & 66.7 & 0.208 \\
\hline \multicolumn{13}{|l|}{ Lymph node } \\
\hline pNO & 43 & 55.8 & 30 & 69.8 & 13 & 30.2 & & 26 & 60.5 & 17 & 39.5 & \\
\hline $\mathrm{pN} 1$ & 24 & 31.2 & 14 & 58.3 & 10 & 41.7 & & 13 & 54.2 & 11 & 45.8 & \\
\hline $\mathrm{pN} 2$ & 6 & 7.8 & 5 & 83.3 & 1 & 16.7 & & 5 & 83.3 & 1 & 16.7 & \\
\hline $\mathrm{pN} 3$ & 2 & 2.6 & 1 & 50.0 & 1 & 50.0 & 0.204 & 0 & 0.0 & 2 & 100.0 & 0.158 \\
\hline Unknown & 2 & 2.6 & 2 & 100.0 & 0 & 0.0 & & 0 & 0.0 & 2 & 100.0 & \\
\hline \multicolumn{13}{|l|}{ Hormonal status } \\
\hline \multicolumn{13}{|l|}{ ER status } \\
\hline Negative & 18 & 23.4 & 10 & 55.6 & 8 & 44.4 & & 11 & 61.1 & 7 & 38.9 & \\
\hline Positive & 59 & 76.6 & 42 & 71.2 & 17 & 28.8 & 0.069 & 33 & 56.0 & 26 & 44.0 & 0.458 \\
\hline \multicolumn{13}{|l|}{ PR status } \\
\hline Negative & 27 & 35.1 & 15 & 55.6 & 12 & 44.4 & & 17 & 63.0 & 10 & 37.0 & \\
\hline Positive & 50 & 64.9 & 37 & 74.0 & 13 & 26.0 & 0.085 & 27 & 54.0 & 23 & 46.0 & 0.299 \\
\hline \multicolumn{13}{|l|}{ HER-2 } \\
\hline Negative & 63 & 81.8 & 42 & 66.7 & 21 & 33.3 & & 35 & 55.6 & 28 & 44.4 & \\
\hline Positive & 14 & 18.2 & 10 & 71.4 & 4 & 28.6 & 0.616 & 9 & 64.3 & 5 & 35.7 & 0.164 \\
\hline $\mathrm{TN}$ & 13 & 16.9 & 8 & 61.5 & 5 & 38.5 & & 9 & 69.2 & 4 & 30.8 & \\
\hline Others & 64 & 83.1 & 44 & 68.8 & 20 & 31.3 & 0.416 & 35 & 54.7 & 29 & 45.3 & 0.971 \\
\hline \multicolumn{13}{|l|}{ Ki-67 } \\
\hline Low $\leq 25 \%$ & 54 & 70.1 & 37 & 68.5 & 17 & 31.5 & & 32 & 59.3 & 22 & 40.7 & \\
\hline High $>25 \%$ & 22 & 28.6 & 14 & 63.6 & 8 & 36.4 & 0.834 & 12 & 54.6 & 10 & 45.4 & 0.668 \\
\hline Unknown & 1 & 1.3 & 1 & 100.0 & 0 & 0.0 & & 0 & 0.0 & 1 & 100.0 & \\
\hline
\end{tabular}

CHI3L1: Chitinase 3 like 1; Nogo-A: neurite outgrowth inhibitor type A; ER: estrogen receptor; PR: progesterone receptor; HER-2: human epidermal growth factor receptor 2; TN: triple negative (no expression of ER, PR and HER-2 receptor).

Statistical analysis. Normal distribution analysis was performed with the Shapiro-Wilk test. The levels of expression of the studied markers were statistically analyzed with the use of Mann-Whitney $U$-test and Kruskal-Wallis test (one-way ANOVA on ranks) using post-hoc Dunn's test. Correlation was calculated using Spearman's test. MantelCox test (Log-rank) was used for survival analysis. Statistically significant $p$-values were $\leq 0.05$. Prism 5.0 (GraphPad, La Jolla, CA, USA) and STATISTICA 12.0 (Statsoft, Tulsa, OK, USA) software was used for statistical analysis.

\section{Results}

IHC expression of CHI3L1, Nogo, and VEGF. The results of the IHC indicated cytoplasmic localization of CHI3L1, NogoA, Nogo-A/B, and NgBR, as well as of selected angiogenesis markers: VEGFA, VEGFC, and VEGFD in IDC cancer cells (Figure 1). Table III shows the intensity of the IHC reactions for the studied antigens, as well as the cut-off points indicated 
Table II. Immunohistochemical reaction intensity (IRS) according to Remmele and Stegner (50). The score results from multiplying immunopositive cell percentage (A) with immunohistochemical reaction intensity $(B) ;(I R S=A x B)$.

\begin{tabular}{lcc}
\hline Points & $\begin{array}{c}\text { Percentage of positively } \\
\text { stained cells (A) }\end{array}$ & $\begin{array}{c}\text { Intensity of color } \\
\text { reaction (B) }\end{array}$ \\
\hline 0 & $0 \%$ & 0 No color reaction \\
1 & $\leq 10 \%$ & 1 Low color intensity \\
2 & $11-50 \%$ & 2 Moderate color intensity \\
3 & $51-80 \%$ & 3 Intense color \\
4 & $>80 \%$ & \\
\hline
\end{tabular}

by the median score. More than $30 \%$ of the analyzed IDC cases were characterized by a high level of CHI3L1 expression. Positive IHC reaction for Nogo-A was reported in 33 (42.86\%) cases. More than half of the cases (49) showed low $\mathrm{NgBR}$ expression. Almost $80 \%$ of cases were characterized by low VEGFA expression, whereas $39(50.6 \%)$ and $41(53.2 \%)$ cases had low expression of VEGFC and VEGFD. The analysis of the obtained results showed a statistically significant positive correlation of Nogo-A and CHI3L1 expression ( $\mathrm{r}=0.474$, $p>0.0001$ ) (Figure 2A) and positive correlation of Nogo-A and VEGFC expression $(\mathrm{r}=0.280, p=0.013)$ (Figure 3B). Additionally, an almost statistically significant correlation of Nogo-A with VEGFA and VEGFD ( $\mathrm{r}=0.211, p=0.065$; $\mathrm{r}=0.192, p=0.094$ ) was observed (Figure $3 \mathrm{~A}$ and $\mathrm{C}$ ). No correlation of CHI3L1 and Nogo-A/B (Figure 2B) and also CHI3L1 and NgBR was observed (Figure 2C).

Analysis with clinical-pathological data. The relationship between the level of expression of CHI3L1, Nogo-A and clinical-pathological patient data are shown in Table I. No differences were observed in the expression of CHI3L1 and Nogo-A depending on tumor grade of malignancy, Ki-67 expression, tumor size, lymph node metastases and distant metastases (pTNM), stage of cancer or status of ER, PR and HER-2 receptors. Also, statistical analysis showed no correlation of Nogo-A expression with the age of patients nor with menopause. The analysis performed did not show a causal link between the expression of CHI3L1 and Nogo-A and patient overall survival (OS) or disease-free survival (DFS) (Table IV).

\section{Discussion}

Multiple in vitro and in vivo studies have suggested the potential involvement of CHI3L1 in angiogenesis associated with carcinogenesis by promoting endothelial cell migration and participating in vascular structure formation $(11,16,40)$. The results of in vitro studies using human microvessel endothelial cells (HMVEC) and U87 human glioma cell line showed a synergistic CHI3L1 and VEGF activity in vascular structure formation $(16,40)$. Studies performed with the use of a mouse model for human breast cancer, colon cancer and glioma, as well as with the patient glioma material, highlighted the role of CHI3L1 in promoting angiogenesis $(11,16,40,54)$. Moreover, in one of our recently published research on IDC, a positive correlation was shown between CHI3L1 and angiogenesis markers such as: CD31, CD34, and VEGFD. This also suggested that there is a link between CHI3L1 and angiogenesis in this type of cancer (15).

Previous breast cancer studies performed on tissue specimens indicated a lack of correlation between CHI3L1 expression and clinical-pathological data, such as: the presence of lymph node metastases, tumor size, patient's age, OS and DFS, which was also confirmed by our results (1215, 55). However, studies on the blood serum of breast cancer patients indicated a correlation between an increased level of CHI3L1 and shorter OS and DFS, which does not exclude the prognostic potential of CHI3L1 in IDC (56-58).

In this work, we showed for the first time, a positive correlation of CHI3L1 with Nogo-A and of Nogo-A with VEGFC, which may suggest a link between Nogo-A and blood vessel formation in breast cancer. This hypothesis is based on the results of studies on the role of CHI3L1 and Nogo-A in the regulation of angiogenesis by MAPK and PI3K/Akt pathways (40-42). These pathways are also activated in VEGF-dependent angiogenesis $(59,60)$. The published results describe Nogo-A as a negative regulator of angiogenesis in the central nervous system (CNS) $(28,61)$. It is believed that by activating Rho$\mathrm{A} /$ Rock/myosin II pathway, Nogo-A plays an inhibitory role in angiogenesis, migration, adhesion and budding of endothelial cells (61). So far, Nogo-A expression on a protein level was found in oligodendrocytes, neurons and glial cells, whereas in endothelial cells Nogo-A expression was observed only at the mRNA level $(28,61)$. In this work, we did not observe any link between the levels of Nogo-A and selected clinical-pathological factors, nor with OS and DFS in IDC. Up until now, there is no literature where similar correlations are described.

In our studies, we did not observe any statistically significant correlations between CHI3L1 and Nogo-A/B or $\mathrm{NgBR}$. It is noteworthy that thus far clear correlations between these proteins have not been described. It has been shown that Nogo-B is involved in blood vessel remodeling through the promotion of HUVEC endothelial cell migration and in inhibition of human aortic vascular smooth muscle cells (HAVSMC) migration (20). In human endothelial cell HUVEC line and in mouse microvascular endothelial cell MVEC line, Nogo-B was identified at the protein level (20, 28, 61). Drożdż et al., have reported that the levels of Nogo-B mRNA and protein expression in the internal membrane of blood vessels from atherosclerotic patients were lower compared to control (62). Zhao et al. described a role of Nogo-B and NgBR in blood vessel formation in zebrafish 


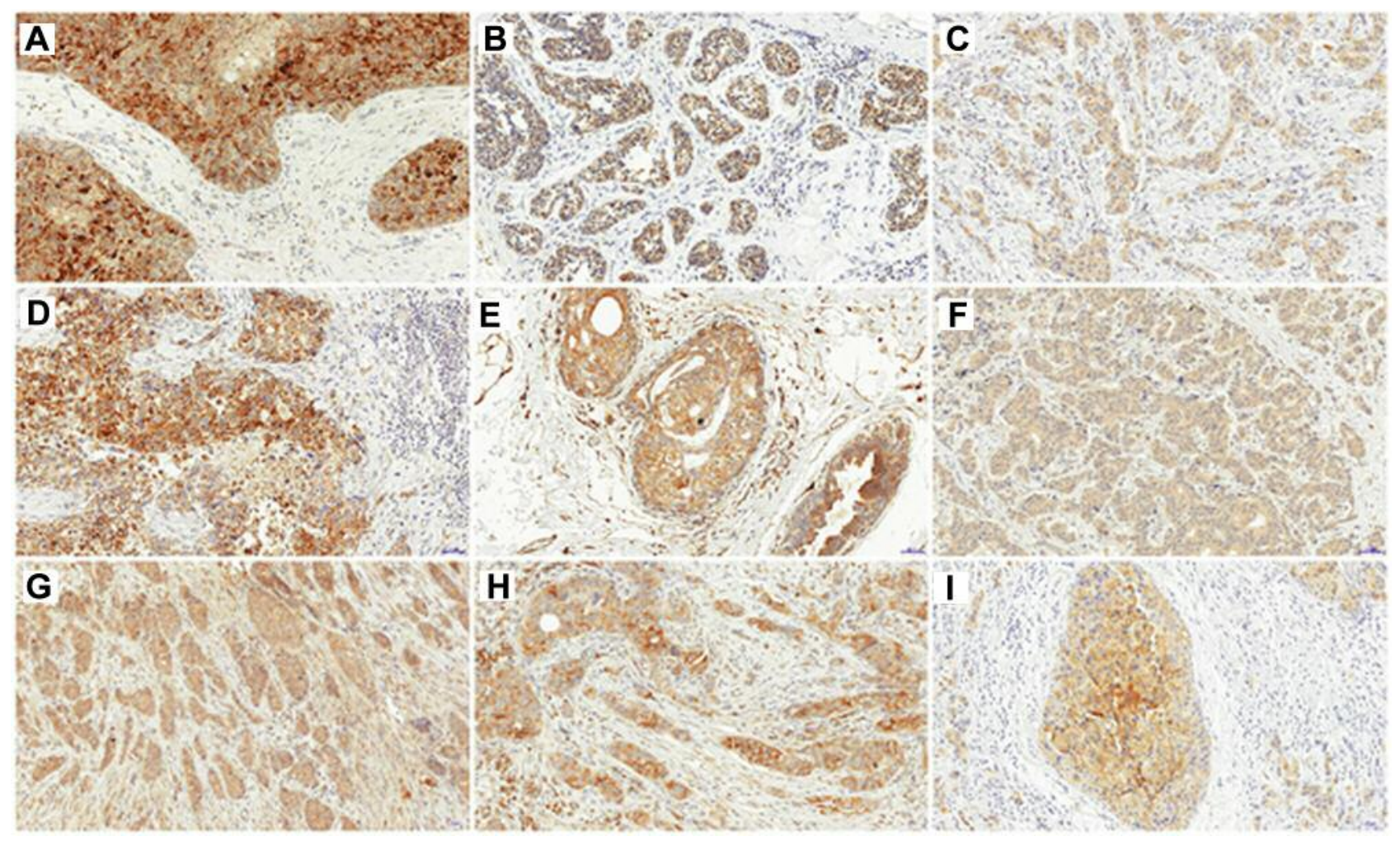

Figure 1. Immunohistochemical reactions (IHC) performed on paraffin sections of invasive ductal breast carcinoma (IDC). Cytoplasmic localization in cancer cells: chitinase 3 like 1 (CHI3L1) (A - intense, $B$ - medium), neurite outgrowth inhibitor type A (Nogo- $A)(D-i n t e n s e, C$ - medium), Nogo$A / B(E)$, receptor for Nogo-B $(N g B R)(F)$, vascular endothelial growth factors: VEGFA $(G), \operatorname{VEGFC}(H)$, and VEGFD (I). Magnification 200x.

Table III. Intensity of evaluated immunohistochemical reactions. Semi-quantitative immunoreactive score (IRS) scale according to Remmele and Stegner (IRS) was used; medians were used as cut-off points.

\begin{tabular}{|c|c|c|c|c|c|}
\hline IHC marker & Cut-off (IRS) & Low expression $(\mathrm{N})$ & $\%$ & High expression $(\mathrm{N})$ & $\%$ \\
\hline CHI3L1 & $0-3$ vs. 4-12 & 52 & 67.5 & 25 & 32.5 \\
\hline Nogo-A & 0 vs. $1-12$ & 44 & 57.1 & 33 & 42.9 \\
\hline Nogo-A/B & $0-6$ vs. 8-12 & 47 & 61.0 & 30 & 39.0 \\
\hline $\mathrm{NgBR}$ & $0-4$ vs. 6-12 & 49 & 63.6 & 28 & 36.4 \\
\hline VEGFA & $0-6$ vs. 8-12 & 60 & 77.9 & 17 & 22.1 \\
\hline VEGFC & $0-4$ vs. 6-12 & 39 & 50.6 & 38 & 49.4 \\
\hline VEGFD & $0-4$ vs. 6-12 & 41 & 53.2 & 36 & 46.8 \\
\hline
\end{tabular}

CHI3L1: Chitinase 3 like 1; Nogo-A: neurite outgrowth inhibitor type A; Nogo-A/B: neurite outgrowth inhibitor type A/B; NgBR: neurite outgrowth inhibitor type B receptor; VEGFA: vessel endothelial growth factor A; VEGFC: vessel endothelial growth factor C; VEGFD: vessel endothelial growth factor $\mathrm{D}$.

embryos (39). Currently, there are no publications on the role of Nogo-B and NgBR in angiogenesis in IDC.

On the other hand, there are many papers emphasizing on the role of Nogo proteins in carcinogenesis. The results of in vitro studies on MCF7 and MCF10AT cell lines showed the impact of Nogo-A on the proliferation and migration of breast cancer cells (63). The results of our studies on non-small cell lung cancer (NSCLC) showed high level of Nogo-A/B expression in squamous cell carcinoma in comparison with adenocarcinoma. Also, low levels of Nogo-A/B expression were reported in higher stage NSCLC (18). Low levels of Nogo-A/B expression in melanoma and increased levels of its expression in gastric cancer were described as an unfavorable prognostic factor 
A

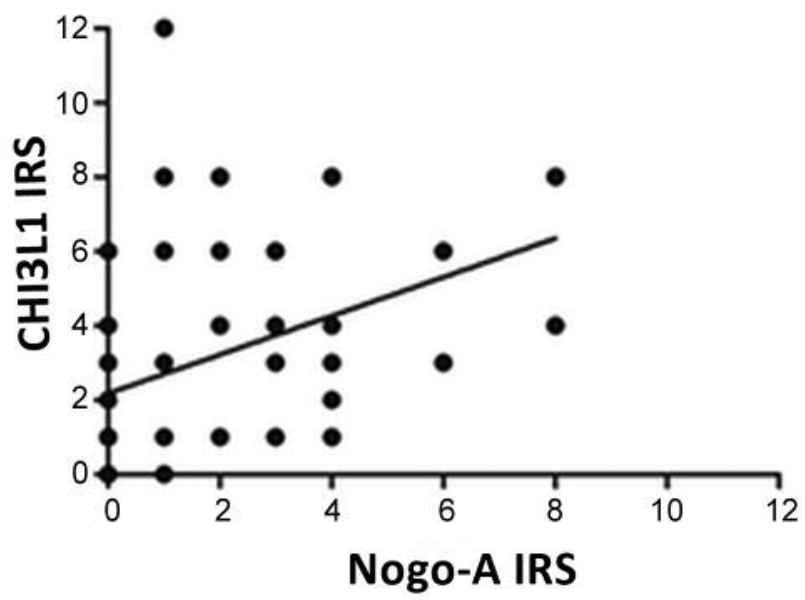

B

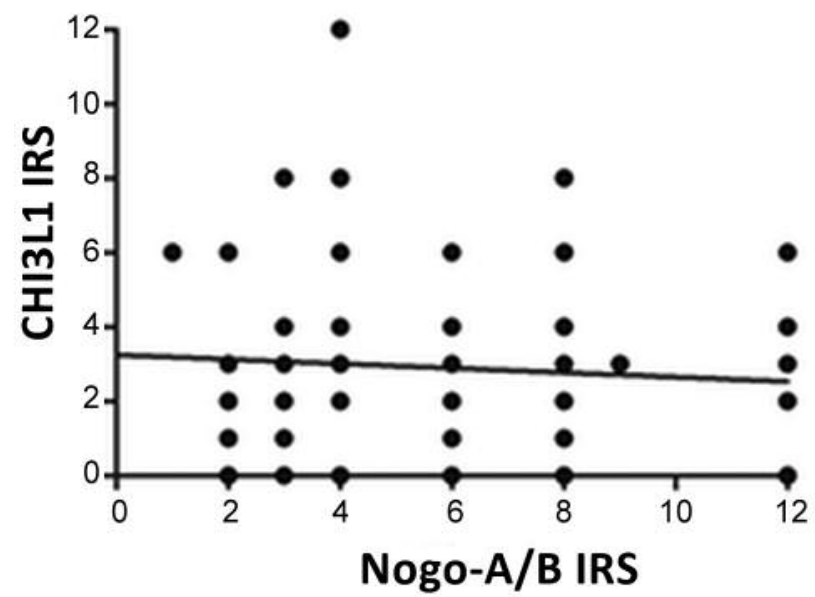

C

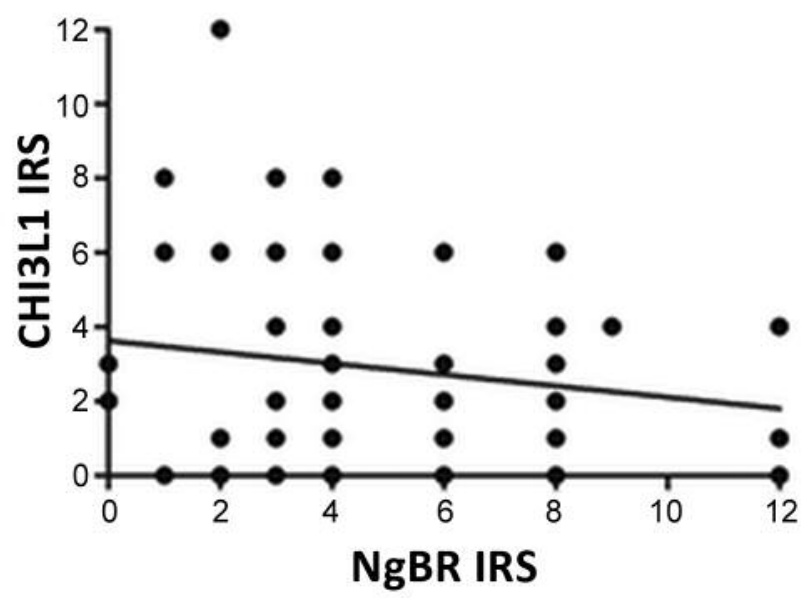

Figure 2. Correlation (IRS) between CHI3L1 (chitinase 3 like 1), Nogo$A, N o g o-A / B$ (neurite outgrowth inhibitor) and $\mathrm{NgBR}$ (neurite outgrowth inhibitor type $B$ receptor) in invasive ductal carcinoma (IDC). A) CHI3L1 vs. Nogo-A: $r=0.474, p<0.0001$; B) CHI3L1 vs. Nogo-A/B: $r=-0.020, p=0.855$; C) CHI3L1 vs. NgBR: $r=-0.116, p=0.314$; Spearman's correlation test, $p<0.05$.

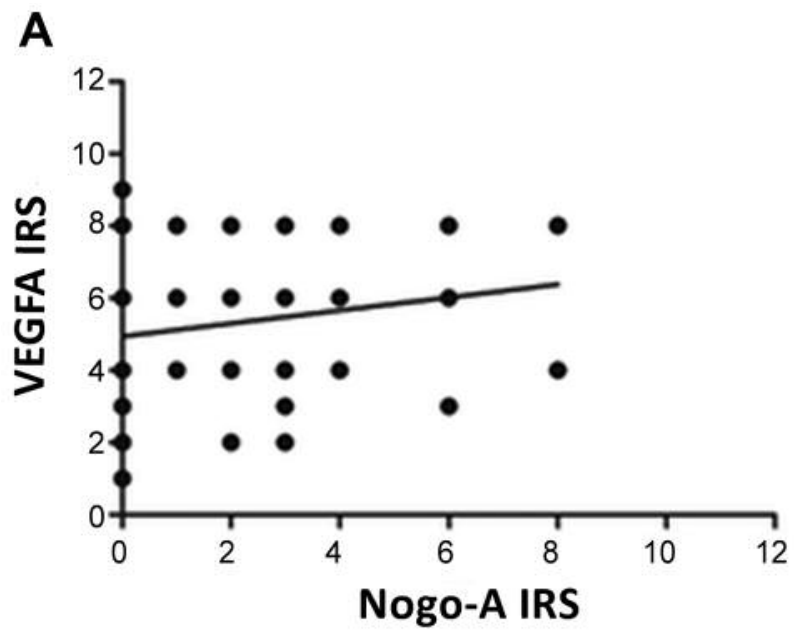

B

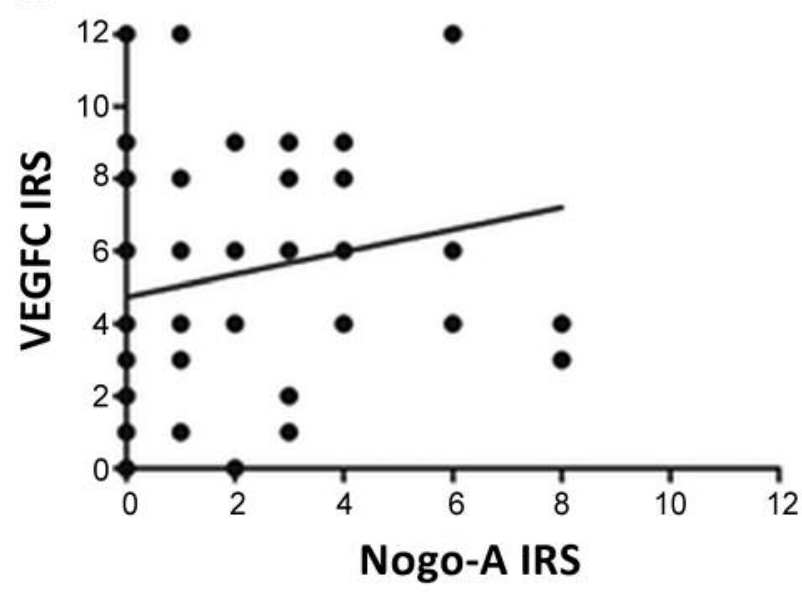

C

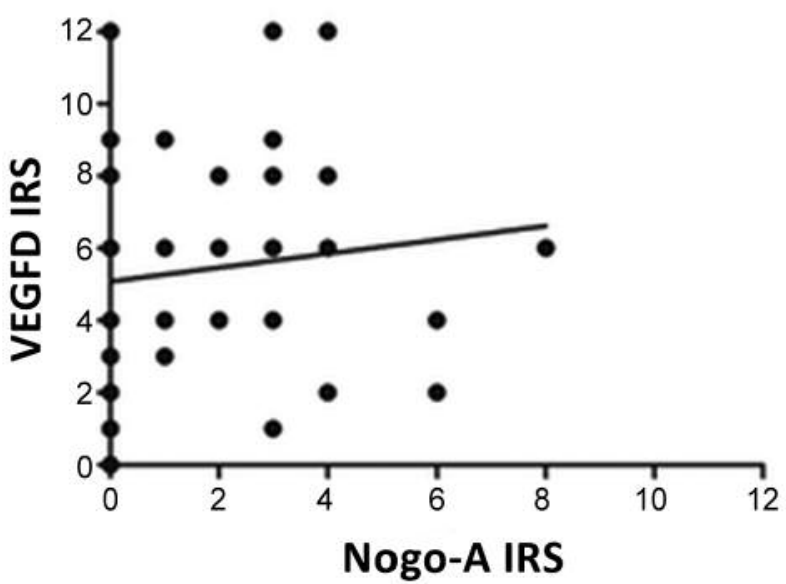

Figure 3. Correlation of (IHC) Nogo-A with vascular endothelial growth factors (VEGFA, VEGFB, VEGFC) in invasive breast carcinoma. A) Nogo-A vs. VEGFA, $r=0.211, p=0.065 ; B$ ) Nogo-A vs. VEGFC, $r=0.280$, $p=0.013$; C) Nogo-A vs. VEGFD, $r=0.192, p=0.094$; Spearman's correlation test, $p<0.05$. 
Table IV. The analysis of overall survival and disease-free survival for 77 patients diagnosed with IDC [Mantel-Cox test (Log-rank)]. Immunohistochemical reactions were evaluated according to Remmele and Stegner score (IRS) (50); medians were used as cut-off points, statistically significant p-values were $<0.05$.

\begin{tabular}{|c|c|c|c|c|c|}
\hline IHC marker & $\mathrm{N}$ & Cut-off (IRS) & HR & $95 \% \mathrm{CI}$ & $p$-Value \\
\hline \multirow[t]{2}{*}{ CHI3LI } & 77 & $0-3$ vs. $4-12$ & 1.367 & $0.665-2.810$ & OS: 0.396 \\
\hline & & & 0.912 & $0.409-2.032$ & DFS: 0.821 \\
\hline \multirow[t]{2}{*}{ Nogo-A } & 77 & 0 vs. $1-12$ & 0.987 & 0.494-1.972 & OS: 0.970 \\
\hline & & & 0.802 & $0.369-1.744$ & DFS: 0.578 \\
\hline
\end{tabular}

CHI3L1: Chitinase 3 like 1; Nogo-A: neurite outgrowth inhibitor type A; OS: overall survival; DFS: disease-free survival; HR: hazard ratio; CI: confidence interval.

$(34,35)$. In our own research on IDC, we showed a higher level of $\mathrm{NgBR}$ in cancer cells in comparison to the control (NBTL), both at mRNA and protein level. Moreover, NgBR expression in IDC was negatively correlated with a degree of histological malignancy and Ki-67, whereas lower levels of $\mathrm{NgBR}$ mRNA may be considered an unfavorable prognostic factor for patient overall survival (36). On the other hand, Wang et al. showed a higher level of $\mathrm{NgBR}$ expression in tumors with higher grade of histological malignancy (II-IV) and positive correlation of $\mathrm{NgBR}$ and survivin expression in IDC (37). Also, a higher $\mathrm{NgBR}$ expression was observed in ER positive $(\mathrm{ER}+)$, as well as in HER2 negative tumors (HER2-) (37). Higher levels of $\mathrm{NgBR}$ expression in hepatocellular carcinoma patients were correlated with shorter OS (38).

Our study suggests that CHI3L1 and Nogo-A may be important in angiogenesis in IDC. CHI3L1 and Nogo-A are supposedly involved, inter alia, in inflammatory processes $(28,48,49)$. We presume that the pro-angiogenic role of CHI3L1 and Nogo-A may be correlated with an inflammatory process associated with cancer. This hypothesis, however, requires further study to evaluate the role of CHI3L1 and Nogo-A in the regulation of PI3K/Akt and MAPK pathways, which are so important in oncogenesis and angiogenesis (40$42,45,64,65)$.

\section{Conclusion}

A correlation between the expression of CHI3L1 and NogoA was found in IDC which indicates a possible involvement of Nogo-A in angiogenesis (positive correlation with VEGFC). These results are a prelude for further study that could precisely determine the function of CHI3L1 and Nogo$\mathrm{A}$ in IDC.

\section{Conflicts of Interest}

The Authors declare that they have no competing interests in regard to this study.

\section{Authors' Contributions}

Design, data collection: AR, AP, JG, AW. Writing of the manuscript: AR. Revision of the manuscript: KJ, PD. All Authors approved the final manuscript.

\section{References}

1 Johansen JS, Jensen BV, Roslind A, Nielsen D and Price PA: Serum ykl-40, a new prognostic biomarker in cancer patients? Cancer Epidemiol Biomarkers Prev 15(2): 194-202, 2006. PMID: 16492905. DOI: 10.1158/1055-9965.EPI-05-0011

2 Johansen JS, Jensen BV, Roslind A and Price PA: Is ykl-40 a new therapeutic target in cancer? Expert Opin Ther Targets 11(2): 219234, 2007. PMID: 17227236. DOI: 10.1517/147282 22.11.2.219

3 Recklies AD, White $\mathrm{C}$ and Ling $\mathrm{H}$ : The chitinase 3-like protein human cartilage glycoprotein 39 (hc-gp39) stimulates proliferation of human connective-tissue cells and activates both extracellular signal-regulated kinase- and protein kinase bmediated signalling pathways. Biochem J 365(Pt 1): 119-126, 2002. PMID: 12071845 . DOI: $10.1042 / \mathrm{BJ} 20020075$

4 Rehli M, Niller HH, Ammon C, Langmann S, Schwarzfischer L, Andreesen R and Krause SW: Transcriptional regulation of chi311, a marker gene for late stages of macrophage differentiation. J Biol Chem 278(45): 44058-44067, 2003. PMID: 12933821. DOI: 10.1074/jbc.M306792200

5 Kzhyshkowska J, Gratchev A and Goerdt S: Human chitinases and chitinase-like proteins as indicators for inflammation and cancer. Biomark Insights 2: 128-146, 2007. PMID: 19662198.

6 Lee CG, Hartl D, Lee GR, Koller B, Matsuura H, Da Silva CA, Sohn MH, Cohn L, Homer RJ, Kozhich AA, Humbles A, Kearley J, Coyle A, Chupp G, Reed J, Flavell RA and Elias JA: Role of breast regression protein 39 (brp-39)/chitinase 3-like-1 in th2 and il-13-induced tissue responses and apoptosis. J Exp Med 206(5): 1149-1166, 2009. PMID: 19414556. DOI: 10.1084/ jem.20081271

7 Malmeström C, Axelsson M, Lycke J, Zetterberg H, Blennow K and Olsson B: Csf levels of ykl-40 are increased in ms and replaces with immunosuppressive treatment. J Neuroimmunol 269(1-2): 87-89, 2014. PMID: 24582001. DOI: 10.1016/ j.jneuroim.2014.02.004

8 Rusak A, Jabłońska K and Dzięgiel P: The role of ykl-40 in a cancerous process. Postepy Hig Med Dosw (Online) 70(0): 1286-1299, 2016. PMID: 28026831 
9 Johansen JS: Studies on serum ykl-40 as a biomarker in diseases with inflammation, tissue remodelling, fibroses and cancer. Dan Med Bull 53(2): 172-209, 2006. PMID: 17087877.

10 Junker N, Johansen JS, Andersen CB and Kristjansen PE: Expression of ykl-40 by peritumoral macrophages in human small cell lung cancer. Lung Cancer 48(2): 223-231, 2005. PMID: 15829322. DOI: 10.1016/j.lungcan.2004.11.011

11 Shao R, Hamel K, Petersen L, Cao QJ, Arenas RB, Bigelow C, Bentley B and Yan W: Ykl-40, a secreted glycoprotein, promotes tumor angiogenesis. Oncogene 28(50): 4456-4468, 2009. PMID: 19767768. DOI: $10.1038 /$ onc. 2009.292

12 Roslind A, Knoop AS, Jensen MB, Johansen JS, Nielsen DL, Price PA and Balslev E: Ykl-40 protein expression is not a prognostic marker in patients with primary breast cancer. Breast Cancer Res Treat 112(2): 275-285, 2008. PMID: 18157633. DOI: $10.1007 / \mathrm{s} 10549-007-9870-7$

13 Shao R, Cao QJ, Arenas RB, Bigelow C, Bentley B and Yan W: Breast cancer expression of ykl-40 correlates with tumour grade, poor differentiation, and other cancer markers. Br J Cancer 105(8): 1203-1209, 2011. PMID: 21934681. DOI: 10.1038/ bjc.2011.347

14 Kang EJ, Jung H, Woo OH, Park KH, Woo SU, Yang DS, Kim AR, Lee JB, Kim YH, Kim JS and Seo JH: Ykl-40 expression could be a poor prognostic marker in the breast cancer tissue. Tumour Biol 35(1): 277-286, 2014. PMID: 23918300. DOI: 10.1007/s13277-013-1036-0

15 Rusak A, Jablonska K, Piotrowska A, Grzegrzolka J, Nowak A, Wojnar A and Dziegiel P: The role of chi311 expression in angiogenesis in invasive ductal breast carcinoma. Anticancer Res 38(6): 3357-3366, 2018. PMID: 29848684. DOI: 10.21873/ anticanres.12602

16 Francescone RA, Scully S, Faibish M, Taylor SL, Oh D, Moral L, Yan W, Bentley B and Shao R: Role of ykl-40 in the angiogenesis, radioresistance, and progression of glioblastoma. J Biol Chem 286(17): 15332-15343, 2011. PMID: 21385870. DOI: $10.1074 / j b c . M 110.212514$

17 Faibish M, Francescone R, Bentley B, Yan W and Shao R: A ykl-40-neutralizing antibody blocks tumor angiogenesis and progression: A potential therapeutic agent in cancers. Mol Cancer Ther 10(5): 742-751, 2011. PMID: 21357475. DOI: 10.1158/1535-7163.MCT-10-0868

18 Pula B, Werynska B, Olbromski M, Muszczynska-Bernhard B, Chabowski M, Janczak D, Zabel M, Podhorska-Okolow M and Dziegiel P: Expression of nogo isoforms and nogo-b receptor (ngbr) in non-small cell lung carcinomas. Anticancer Res 34(8): 4059-4068, 2014. PMID: 25075030.

19 Chiurchiù V, Maccarrone $\mathrm{M}$ and Orlacchio A: The role of reticulons in neurodegenerative diseases. Neuromolecular Med 16(1): 3-15, 2014. PMID: 24218324. DOI: 10.1007/s12017-0138271-9

20 Acevedo L, Yu J, Erdjument-Bromage H, Miao RQ, Kim JE, Fulton D, Tempst P, Strittmatter SM and Sessa WC: A new role for nogo as a regulator of vascular remodeling. Nat Med 10(4): 382-388, 2004. PMID: 15034570. DOI: 10.1038/nm1020

21 Schwab ME: Nogo and axon regeneration. Curr Opin Neurobiol 14(1): 118-124, 2004. PMID: 15018947. DOI: 10.1016/j.conb. 2004.01.004

22 Schanda K, Hermann M, Stefanova N, Gredler V, Bandtlow C and Reindl M: Nogo-b is associated with cytoskeletal structures in human monocyte-derived macrophages. BMC Res Notes 4: 6, 2011. PMID: 21235733. DOI: 10.1186/1756-0500-4-6
23 Tagami S, Eguchi Y, Kinoshita M, Takeda M and Tsujimoto Y: A novel protein, rtn-xs, interacts with both bcl-xl and bcl-2 on endoplasmic reticulum and reduces their anti-apoptotic activity. Oncogene 19(50): 5736-5746, 2000. PMID: 11126360. DOI: 10.1038/sj.onc. 1203948

24 Zhao B, Xu B, Hu W, Song C, Wang F, Liu Z, Ye M, Zou H and Miao QR: Comprehensive proteome quantification reveals ngbr as a new regulator for epithelial-mesenchymal transition of breast tumor cells. J Proteomics 112: 38-52, 2015. PMID: 25173099. DOI: 10.1016/j.jprot.2014.08.007

25 Kuang E, Wan Q, Li X, Xu H, Zou T and Qi Y: Er stress triggers apoptosis induced by nogo-b/asy overexpression. Exp Cell Res 312(11): 1983-1988, 2006. PMID: 16687140. DOI: 10.1016/ j.yexcr.2006.02.024

26 Jia S, Qiao X, Ye J, Fang X, Xu C, Cao Y and Zheng M: Nogoc regulates cardiomyocyte apoptosis during mouse myocardial infarction. Cell Death Dis 7(10): e2432, 2016. PMID: 27763637. DOI: $10.1038 /$ cddis.2016.331

27 Hao CQ, Zhou Y, Wang JP, Peng MJ, Xie YM, Kang WZ, Sun L, Wang PZ, Wan CL, He L, Cai L and Jia ZS: Role of nogo-a in the regulation of hepatocellular carcinoma smmc-7721 cell apoptosis. Mol Med Rep 9(5): 1743-1748, 2014. PMID: 246268 42. DOI: $10.3892 / \mathrm{mmr} .2014 .2050$

28 Seiler S, Di Santo S and Widmer HR: Non-canonical actions of nogo-a and its receptors. Biochem Pharmacol 100: 28-39, 2016. PMID: 26348872. DOI: 10.1016/j.bcp.2015.08.113

29 Miao RQ, Gao Y, Harrison KD, Prendergast J, Acevedo LM, Yu J, $\mathrm{Hu}$ F, Strittmatter SM and Sessa WC: Identification of a receptor necessary for nogo-b stimulated chemotaxis and morphogenesis of endothelial cells. Proc Natl Acad Sci USA 103(29): 10997-11002, 2006. PMID: 16835300. DOI: $10.1073 /$ pnas.0602427103

30 Dupuis L, Gonzalez de Aguilar JL, di Scala F, Rene F, de Tapia M, Pradat PF, Lacomblez L, Seihlan D, Prinjha R, Walsh FS, Meininger V and Loeffler JP: Nogo provides a molecular marker for diagnosis of amyotrophic lateral sclerosis. Neurobiol Dis 10(3): 358-365, 2002. PMID: 12270696

31 Satoh J, Onoue H, Arima K and Yamamura T: Nogo-a and nogo receptor expression in demyelinating lesions of multiple sclerosis. J Neuropathol Exp Neurol 64(2): 129-138, 2005. PMID: 15751227

32 Zhong J, Fan S, Yan Z, Xiao S, Wan L, Chen C, Zhong S, Liu L and Liu J: Effects of nogo-a silencing on tnf- $\alpha$ and il-6 secretion and th downregulation in lipopolysaccharide-stimulated pc12 cells. Biomed Res Int 2015: 817914, 2015. PMID: 26583134. DOI: $10.1155 / 2015 / 817914$

33 Schawkat K, Di Santo S, Seiler S, Ducray AD and Widmer HR: Loss of nogo-a-expressing neurons in a rat model of parkinson's disease. Neuroscience 288: 59-72, 2015. PMID: 25554426 DOI: 10.1016/j.neuroscience.2014.12.035

34 Calik J, Pula B, Piotrowska A, Wojnar A, Witkiewicz W, Grzegrzolka J, Podhorska-Okolow M and Dziegiel P: Prognostic significance of nogo-a/b and nogo-b receptor expression in malignant melanoma - a preliminary study. Anticancer Res 36(7): 3401-3407, 2016. PMID: 27354599

35 Chi C, Liu N, Yue L, Qi WW, Xu LL and Qiu WS: Rtn4/nogo is an independent prognostic marker for gastric cancer: Preliminary results. Eur Rev Med Pharmacol Sci 19(2): 241-246, 2015. PMID: 25683937

36 Pula B, Olbromski M, Owczarek T, Ambicka A, Witkiewicz W, Ugorski M, Rys J, Zabel M, Dziegiel P and Podhorska-Okolow M: Nogo-b receptor expression correlates negatively with 
malignancy grade and ki-67 antigen expression in invasive ductal breast carcinoma. Anticancer Res 34(9): 4819-4828, 2014. PMID: 25202063

37 Wang B, Zhao B, North P, Kong A, Huang J and Miao QR: Expression of ngbr is highly associated with estrogen receptor alpha and survivin in breast cancer. PLoS One 8(11): e78083, 2013. PMID: 24223763. DOI: 10.1371/journal.pone.0078083

38 Dong C, Zhao B, Long F, Liu Y, Liu Z, Li S, Yang X, Sun D, Wang H, Liu Q, Liang R, Li Y, Gao Z, Shao S, Miao QR and Wang L: Nogo-b receptor promotes the chemoresistance of human hepatocellular carcinoma via the ubiquitination of p53 protein. Oncotarget 7(8): 8850-8865, 2016. PMID: 26840457. DOI: $10.18632 /$ oncotarget.7091

39 Zhao B, Chun C, Liu Z, Horswill MA, Pramanik K, Wilkinson GA, Ramchandran R and Miao RQ: Nogo-b receptor is essential for angiogenesis in zebrafish via akt pathway. Blood 116(24): 5423-5433, 2010. PMID: 20813898. DOI: 10.1182/blood-201002-271577

40 Shao R, Taylor SL, Oh DS and Schwartz LM: Vascular heterogeneity and targeting: The role of ykl-40 in glioblastoma vascularization. Oncotarget 6(38): 40507-40518, 2015. PMID: 26439689. DOI: 10.18632/oncotarget.5943

41 Raiker SJ, Lee H, Baldwin KT, Duan Y, Shrager P and Giger RJ: Oligodendrocyte-myelin glycoprotein and nogo negatively regulate activity-dependent synaptic plasticity. J Neurosci 30(37): 12432-12445, 2010. PMID: 20844138. DOI: 10.1523/ JNEUROSCI.0895-10.2010

42 Kilic E, ElAli A, Kilic U, Guo Z, Ugur M, Uslu U, Bassetti CL, Schwab ME and Hermann DM: Role of nogo-a in neuronal survival in the reperfused ischemic brain. J Cereb Blood Flow Metab 30(5): 969-984, 2010. PMID: 20087369. DOI: 10.1038/ jcbfm.2009.268

43 Tripathi KP, Piccirillo M and Guarracino MR: An integrated approach to infer cross-talks between intracellular protein transport and signaling pathways. BMC Bioinformatics 19(2): 58, 2018. PMID: 29536825. DOI: 10.1186/s12859-018-2036-2

44 Krześlak A: Akt kinase: A key regulator of metabolism and progression of tumors. Postepy Hig Med Dosw (Online) 64: 490-503, 2010. PMID: 20966507.

45 Okkenhaug K, Graupera M and Vanhaesebroeck B: Targeting pi3k in cancer: Impact on tumor cells, their protective stroma, angiogenesis, and immunotherapy. Cancer Discov 6(10): 1090-1105, 2016. PMID: 27655435. DOI: 10.1158/2159-8290.CD-16-0716

46 Sacewicz I, Wiktorska M, Wysocki T and Niewiarowska J: Mechanisms of cancer angiogenesis. Postepy Hig Med Dosw (Online) 63: 159-168, 2009. PMID: 19502677.

47 Burotto M, Chiou VL, Lee JM and Kohn EC: The mapk pathway across different malignancies: A new perspective. Cancer 120(22): 3446-3456, 2014. PMID: 24948110. DOI: 10.1002/cncr.28864

48 Shao R: Ykl-40 acts as an angiogenic factor to promote tumor angiogenesis. Front Physiol 4: 122, 2013. PMID: 23755018. DOI: $10.3389 /$ fphys.2013.00122

49 Li TM, Liu SC, Huang YH, Huang CC, Hsu CJ, Tsai CH, Wang SW and Tang CH: Ykl-40-induced inhibition of mir-590-3p promotes interleukin-18 expression and angiogenesis of endothelial progenitor cells. Int J Mol Sci 18(5), 2017. PMID: 28448439. DOI: $10.3390 /$ ijms 18050920

50 Remmele W and Stegner HE: Recommendation for uniform definition of an immunoreactive score (irs) for immuno- histochemical estrogen receptor detection (er-ica) in breast cancer tissue. Pathologe 8(3): 138-140, 1987. PMID: 3303008.

51 Hammond ME, Hayes DF, Dowsett M, Allred DC, Hagerty KL, Badve S, Fitzgibbons PL, Francis G, Goldstein NS, Hayes M, Hicks DG, Lester S, Love R, Mangu PB, McShane L, Miller K, Osborne CK, Paik S, Perlmutter J, Rhodes A, Sasano H, Schwartz JN, Sweep FC, Taube S, Torlakovic EE, Valenstein P, Viale G, Visscher D, Wheeler T, Williams RB, Wittliff JL, Wolff AC, Oncology ASoC and Pathologists CoA: American society of clinical oncology/college of american pathologists guideline recommendations for immunohistochemical testing of estrogen and progesterone receptors in breast cancer (unabridged version). Arch Pathol Lab Med 134(7): e48-72, 2010. PMID: 20586616. DOI: 10.1043/1543-2165-134.7.e48

52 Wolff AC, Hammond ME, Hicks DG, Dowsett M, McShane LM, Allison KH, Allred DC, Bartlett JM, Bilous M, Fitzgibbons P, Hanna W, Jenkins RB, Mangu PB, Paik S, Perez EA, Press MF, Spears PA, Vance GH, Viale G, Hayes DF, Oncology ASoC and Pathologists CoA: Recommendations for human epidermal growth factor receptor 2 testing in breast cancer: American society of clinical oncology/college of american pathologists clinical practice guideline update. Arch Pathol Lab Med 138(2): 241-256, 2014. PMID: 24099077. DOI: 10.5858/arpa.20130953-SA

53 Królicka A, Kobierzycki C, Puła B, Podhorska-Okołów M, Piotrowska A, Rzeszutko M, Rzeszutko W, Rabczyński J, Domosławski P, Wojtczak B, Dawiskiba J and Dzięgiel P: Comparison of metallothionein $(\mathrm{mt})$ and ki-67 antigen expression in benign and malignant thyroid tumours. Anticancer Res 30(12): 4945-4949, 2010. PMID: 21187474.

54 Shao R, Francescone R, Ngernyuang N, Bentley B, Taylor SL, Moral L and Yan W: Anti-ykl-40 antibody and ionizing irradiation synergistically inhibit tumor vascularization and malignancy in glioblastoma. Carcinogenesis 35(2): 373-382, 2014. PMID: 24282289. DOI: $10.1093 /$ carcin/bgt380

$55 \mathrm{Kim}$ SH, Das K, Noreen S, Coffman F and Hameed M: Prognostic implications of immunohistochemically detected ykl40 expression in breast cancer. World J Surg Oncol 5: 17, 2007. PMID: 17286869. DOI: 10.1186/1477-7819-5-17

56 Wan G, Xiang L, Sun X, Wang X, Li H, Ge W and Cao F: Elevated ykl-40 expression is associated with a poor prognosis in breast cancer patients. Oncotarget 8(3): 5382-5391, 2017. PMID: 28036271. DOI: 10.18632/oncotarget.14280

57 Jensen BV, Johansen JS and Price PA: High levels of serum her$2 /$ neu and ykl-40 independently reflect aggressiveness of metastatic breast cancer. Clin Cancer Res 9(12): 4423-4434, 2003. PMID: 14555515.

58 Johansen JS, Christensen IJ, Riisbro R, Greenall M, Han C, Price PA, Smith K, Brünner N and Harris AL: High serum ykl40 levels in patients with primary breast cancer is related to short recurrence free survival. Breast Cancer Res Treat $80(1)$ : 15-21, 2003. PMID: 12889595. DOI: 10.1023/A:1024431000710

59 Barańska P, Jerczyńska $\mathrm{H}$ and Pawłowska Z: Vascular endothelial growth factor--structure and functions. Postepy Biochem 51(1): 12-21, 2005. PMID: 16209337.

60 Namiecińska M, Marciniak K and Nowak JZ: Vegf as an angiogenic, neurotrophic, and neuroprotective factor. Postepy Hig Med Dosw (Online) 59: 573-583, 2005. PMID: 16407796. 
61 Wälchli T, Pernet V, Weinmann O, Shiu JY, Guzik-Kornacka A, Decrey G, Yüksel D, Schneider H, Vogel J, Ingber DE, Vogel V, Frei K and Schwab ME: Nogo-a is a negative regulator of cns angiogenesis. Proc Natl Acad Sci USA 110(21): E1943-1952, 2013. PMID: 23625008. DOI: 10.1073/pnas.1216203110

62 Drożdż K, Grzegorek I, Chmielewska M, Gomułkiewicz A, Jabłońska K, Piotrowska A, Karczewski M, Janczak D, Patrzałek D, Dzięgiel P and Szuba A: Nogo-b expression, in arterial intima, is impeded in the early stages of atherosclerosis in humans. APMIS 122(9): 742-749, 2014. PMID: 24372562. DOI: 10.1111/apm.12212

63 Hatakeyama J, Wald JH, Rafidi H, Cuevas A, Sweeney C and Carraway KL: The er structural protein rtn4a stabilizes and enhances signaling through the receptor tyrosine kinase erbb3. Sci Signal 9(434): ra65, 2016. PMID: 27353365. DOI: 10.1126/ scisignal.aaf 1604
64 Zhang W and Liu HT: Mapk signal pathways in the regulation of cell proliferation in mammalian cells. Cell Res 12(1): 9-18, 2002. PMID: 11942415. DOI: 10.1038/sj.cr.7290105

65 Ali K, Soond DR, Pineiro R, Hagemann T, Pearce W, Lim EL, Bouabe H, Scudamore CL, Hancox T, Maecker H, Friedman L, Turner M, Okkenhaug K and Vanhaesebroeck B: Inactivation of pi(3)k p110 breaks regulatory t-cell-mediated immune tolerance to cancer. Nature 510(7505): 407-411, 2014. PMID: 24919154. DOI: $10.1038 /$ nature 13444
Received March 2, 2019

Revised April 18, 2019

Accepted April 19, 2019 